\title{
CAPITALISMO AGRÁRIO E MOVIMENTOS CAMPESINOS NO PARAGUAI
}

\author{
Agrarian capitalism and peasant movements in Paraguay
}

\author{
ISAIAS AlBERTIN DE MORAES E \\ FERNANDO ANTONIO DA COSTA VIEIRA
}

http://dx.doi.org/10.1590/S0103-21862015000200008

Isaias Albertin de Moraes é mestre em Ciência Política pelo Instituto Universitário de Pesquisas do Rio de Janeiro da Universidade Candido Mendes (luperj/Ucam) e pesquisador do Grupo Movimentos Sociais e Mídia: Embates e Aproximações, do luperj/Ucam (isaiasalm@gmail.com).

Fernando Antonio da Costa Vieira é doutor em Sociologia pela Universidade Federal do Rio de Janeiro (UFRJ), pós-doutor em Educação pela Universidade Federal Fluminense (UFF), professor do Programa de Pós-Graduação em Sociologia Política e coordenador do Grupo Movimentos Sociais e Mídia: Embates e Aproximações, do luperj/Ucam (fermavieira@uol.com.br). Artigo recebido em 29 de junho e aprovado para publicação em 29 de setembro de 2015. 


\title{
RESUMO
}

0 artigo busca analisar, por meio de levantamento bibliográfico e documental, o desenvolvimento do capitalismo rural e os movimentos sociais campesinos no Paraguai. Primeiramente, a pesquisa procura abordar a matriz empresarial-monopolista-agroexportadora de ocupação e de exploração da terra no Paraguai, com a significativa influência de ruralistas brasileiros, em detrimento da matriz familiar-cooperativista-alimentícia. Na segunda parte, empenha-se em apresentar os principais movimentos sociais campesinos do país, seus embates e meios de atuação. Por fim, demonstra a importância destes últimos para a democratização da terra, a soberania e a segurança alimentar paraguaia.

Palavras-CHAVE: Paraguai, exploração fundiária, movimentos sociais campesinos.

\begin{abstract}
The article uses bibliographical and documentary data to analyse the development of rural capitalism and peasant social movements in Paraguay. Firstly the research studies the corporate-monopolist-agroexporting model of occupation and exploitation of the land in Paraguay, with a significant influence of Brazilian ruralists, in detriment of a familiar-cooperative-feeding model. In the second part, it presents the main peasant social movements in the country, their struggles and mechanisms of action. Finally, it demonstrates the importance of these movements to the democratization of the land, the sovereignty and the food security of Paraguay.
\end{abstract}

KEY- WORDS: Paraguay, land exploitation, peasant social movements.

\section{RÉSUMÉ}

L'article s'appuie sur une recherche bibliographique et documentale pour analyser le dévéloppement du capitalisme rural et des mouvements sociaux paysans au Paraguay. On analyse d'abord le modèle entrepreneur-monopoliste-agroexportateur de l'occupation et de l'exploitation de la terre au Paraguay, influencé par les agriculteurs brésiliens, au détriment du modèle familier-coopératif-alimentaire. Ensuite on présente les principaux mouvements sociaux paysans du pays, leurs luttes et leurs méchanismes d'action. Finalement, on démontre l'importance significative de ces derniers pour la démocratisation de la terre, la souveraineté et la sécurité alimentaire du Paraguay.

Mots-CLÉS: Paraguay, exploitation de la terre, mouvements sociaux paysans. 


\section{INTRODUÇÃO}

República do Paraguai, com uma área de $406.752 \mathrm{~km}^{2}$, é um dos menores países da
América do Sul. Seu Produto Interno Bruto - PIB, no ano de 2013, foi de US\$ 26.8 bilhões, o terceiro menor do continente, à frente somente do Suriname e da Guiana. A população do país é de aproximadamente 6,8 milhões de habitantes e está concentrada especialmente na região sudeste, sendo que 39,1\% vivem no campo (Paraguay, DGEEC, 2013; Banco Mundial, 2013). De acordo com o mais recente censo agropecuário, 80\% da terra, ou seja, 24,5 dos 31 milhões de hectares cultiváveis se concentram nas mãos de 1,6\% dos proprietários (Paraguay, CAN, 2008). Esse cenário faz com que o Paraguai seja um dos países onde há maior desigualdade de acesso à terra no mundo, com Índice Gini da terra de 0,94 (Guereña \& Riquelme, 2013: 8).

Para investigar a estrutura fundiária e o desenvolvimento do capitalismo rural no Paraguai, este estudo formulou duas categorias de análise. A primeira, embasada na dimensão espacial da terra, foi organizada em três subdivisões: grandefúndio, mediofúndio e pequenofúndio. A segunda foi alicerçada no modo de exploração capitalista realizado no mundo rural paraguaio e se desmembra em duas matrizes: a empresarial-monopolista-agroexportadora e a familiar-cooperativista-alimentícia. Ambas as gradações foram elaboradas com certo paroxismo neologístico, mas são didaticamente práticas para classificar territorialmente e produtivamente qualquer propriedade agrária. A nomenclatura voltada para o tamanho da empresa rural será operacionalizada da seguinte forma: grandefúndio: áreas rurais maiores que 500 hectares; mediofúndio: áreas de 50 a 500 hectares; e pequenofúndio: áreas com menos de 50 hectares. ${ }^{1}$ Os conceitos de matriz produtiva rural empresarial-monopolista-agroexportadora e familiar-cooperativista-alimentícia serão apresentados ao longo do texto.

De acordo com a classificação aplicada e segundo dados oficiais do governo paraguaio, da área cultivável do país, $84,8 \%$ são grandefúndios, sendo que $40,7 \%$ destes têm mais de 10 mil hectares. Os mediofúndios representam somente 7,4\%, enquanto os pequenofúndios correspondem a 7,8\%. Isso faz com que mais de 300 mil famílias de camponeses estejam desprovidas de terras (FAO, 2011; Paraguay, CAN, 2008). 
A latifundização paraguaia permitiu, por um lado, que os grandes complexos agroindustriais atuassem de forma intensiva, acumulando fortunas, batendo recordes na exportação e contribuindo com 19,7\% do PIB do país. A agricultura representa 5.001.226 milhões de hectares no Paraguai, sendo que 61,58\% da área estão ocupados pela soja. A pecuária é extensiva e domina 17.837.589 hectares, com mais de 13 milhões de cabeças de gado, fazendo do país o sétimo maior exportador de carne do mundo (SENACSA, 2014; Paraguay, Síntesis Estadística Producción Agropecuaria, 2012-2013).

Por outro lado, parte expressiva da população paraguaia não tem acesso aos principais produtos agrícolas presentes na pauta de exportação do país, pois vive em grande precariedade. 0 Paraguai ocupa a posição 111 das 187 nações avaliadas no Índice de Desenvolvimento Humano do PNUD (PNUD, 2013). Atualmente, 32,4\% dos paraguaios são pobres e 18\% vivem na extrema pobreza (com menos de US\$2 por dia). No campo, esses percentuais são respectivamente $44,8 \%$ e $29,6 \%$, o que significa que quase $75 \%$ dos moradores rurais vivem em situação de pobreza (Paraguay, DGEEC, 2013; IICA, 2012).

Para compreender o desenvolvimento do capitalismo rural paraguaio, a adoção do crescimento voltado para fora, que resultou no atual modelo empresarial-monopolista-agroexportador escolhido pelo país e viabilizado principalmente no grandefúndio, é necessário interpretar essencialmente o momento político e socioeconômico enfrentado pela República do Paraguai no pós-Segunda Guerra Mundial.

\section{HiSTORIOGRAFIA RECENTE DA CONCENTRAÇÃO FUNDIÁRIA PARAGUAIA}

E m 1954, o General Alfredo Stroessner Matiauda, que possuía grande prestígio por sua atuação na Guerra do Chaco (1932-1935), assumiu o comando do Paraguai, que enfrentava uma conturbada crise política - em um curto período de seis anos o país passara por sete mandatários. Após liderar, com a colaboração dos estadunidenses receosos da ameaça comunista na região, o golpe militar que retirou Federico Chaves Careaga da presidência, Stroessner conseguiu, com a cooperação da Asociación Nacional Republicana, mais conhecida como Partido Colorado, criar uma junta governamental que elegeu provisoriamente Tomás Romero Pereira presidente do país. Após três meses, entretanto, o próprio General assumiu o comando da nação e estabilizou o Paraguai à custa de severas perseguições políticas, congelamentos salariais, elevação de preços de diversos bens, inclusive primários, e com o apoio do Fundo Monetário Internacional - FMI (Nickson, 2010: 265-266). 
Stroessner, que se manteria no poder por 35 anos (1954-1989), foi reeleito em votações fraudulentas por sete mandatos consecutivos. Isso fez com que, diferentemente das ditaduras militares do Brasil (1964-1985) e da Argentina (1976-1983), no Paraguai não existisse uma alternância de governantes. Houve uma centralidade na figura de Stroessner, que se tornou até mesmo nome de cidade - Puerto Presidente Stroessner, rebatizada em 1989 com o nome de Ciudad del Este.

Na política externa, Stroessner ajudou a compor no Cone Sul um cinturão anticomunista. Uma de suas medidas foi a materialização da Operação Condor (1974), iniciativa realizada em conjunto com a ditadura chilena de Augusto José Ramón Pinochet Ugart, que posteriormente recebeu a adesão brasileira e argentina. Outra ação de sua chancelaria foi oferecer aos Estados Unidos, mais de uma vez, suporte militar na Guerra do Vietnã (1954-1975) e na ocupação de São Domingos em 1965, além do apoio constante nos principais fóruns multilaterais.

Além dos EUA, outro país que ganhou destaque na política externa do governo ditatorial paraguaio foi o Brasil. Diferentemente do presidente deposto, Federico Chaves, que defendia uma maior aproximação político-econômica com a Argentina, o General Stroessner era simpatizante dos estreitamentos relacionais com o Brasil. 0 ditador via na aproximação brasileira maior possibilidade de parcerias econômicas, além de novas rotas de exportação, quebrando, assim, a secular dependência paraguaia do Porto de Buenos Aires.

Em 1956, Stroessner empossou assim como ministro das Relações Exteriores o então embaixador do Paraguai no Brasil, Raul Sapeña Pastor Guérin, que permaneceria no cargo até 1976. Durante sua chancelaria, o Paraguai assinou importantes tratados com o Brasil, selando definitivamente as interrelações entre os dois países. Como exemplos, podem ser citados a construção da Ponte Internacional da Amizade (1956), ligando Foz do Iguaçu e Puerto Presidente Stroessner; o convênio para o estabelecimento de um entreposto de depósito franco paraguaio no porto de Paranaguá (1956); a interligação rodoviária entre o Paraguai e o litoral do Paraná (1969); e as obras da Usina Binacional de Itaipu (1973).

Na economia, as medidas de austeridade e os recursos oriundos do FMI, a despeito do agravamento social proporcionado, trouxeram certa estabilidade ao Paraguai. 0 país teve seu PIB aumentado substancialmente entre as décadas de 1960 e 1970, mas, como quase todos os modelos nacionalistas da América Latina, o crescimento não veio acompanhado de desenvolvimento, tendo havido inclusive uma drástica elevação da dívida externa.

Pode-se afirmar que as principais heranças econômicas de Stroessner foram a transformação do país em um porto seguro do comércio de produtos contrabandeados, a inauguração da Usina Hidrelétrica Binacional de Itaipu² e o modelo fundiário concentrador e agroexportador de monocultura. Este último se deveu, em grande parte, a dois aspectos correlacionados 
entre si. 0 primeiro ligava-se ao expressivo crescimento econômico que o Paraguai vinha apresentando e estava diretamente relacionado com as grandes obras de infraestrutura e com o aumento do fluxo de exportações de produtos agropecuários para as nações europeias, que ainda se recuperavam economicamente da Segunda Guerra Mundial. 0 segundo, em consonância com a lógica geoeconômica de exportador de bens primários, resultado da adoção do crescimento para fora, em que o Paraguai se estabeleceu no capitalismo mundial, foi a modificação do Estatuto Agrário por Stroessner no final dos anos 1950, permitindo a venda de terras a estrangeiros. Essa política estava inserida no programa desenvolvimentista e de modernização da economia paraguaia e estimulava o povoamento nas áreas de fronteira com o Brasil por meio da agricultura extensiva.

0 regime de Stroessner, dessa maneira, incentivou fortemente a ida de brasileiros para a região, permitindo sua entrada livre no país, sem a exigência de documentação imposta para outras nacionalidades. Em 1967, ademais, foi abolida a lei federal que proibia a comercialização de terras por estrangeiros na faixa de 150 quilômetros das áreas fronteiriças. Isso fez com que o número de imigrantes brasileiros crescesse significativamente nessas regiões, criando assim o berço para futuros embates sociais e geopolíticos.

A colonização e a ocupação da região leste do Paraguai foram chamadas de marcha hacia el este. 0 programa tinha como uma de suas ações a distribuição de terras por meio do Instituto de Bienestar Rural - IBR, órgão fundiário do governo paraguaio criado em 1963. 0 IBR foi encarregado da fomentação oficial da colonização das áreas pouco povoadas do país, particularmente a região leste da bacia do rio Paraguai e a região fronteiriça da bacia do Rio Paraná.

Na região leste da bacia do rio Paraguai, o IBR forneceu lotes de até 20 hectares para agricultores familiares. Estes chegaram a produzir, para subsistência, milho, mandioca e feijão, e para venda, algodão e fumo. Os solos das áreas, contudo, necessitavam de correções para uma produção agrícola eficiente, os assentados não tinham acesso a assistência técnica ou a créditos, e os lotes careciam de ligações diretas com as cadeias de comercialização. Além disso, a região não contava com a mínima infraestrutura básica, como estradas, escolas, centros de saúde, segurança e energia. Tais fatores, bem como a dinâmica do mercado interno e externo dos bens primários produzidos, contribuíram para a paulatina deterioração das condições de vida do campesinato local e para a futura latifundização das propriedades rurais (Galeano, 1990: 19-49; Frutos, 1982: 115).

Na fronteira com o Brasil, as terras próximas da bacia do rio Paraná apresentavam solos derivados de basaltos, ou seja, altamente produtivos. O IBR, nessa ocasião, foi responsável pela facilitação do acesso de importantes membros do Partido Colorado e de oficias 
das forças armadas às novas propriedades rurais. 0 órgão incentivou, além disso, a ida de colonizadores estrangeiros que, segundo o governo, proporcionariam a modernização da deficiente agricultura de subsistência paraguaia. As medidas resultaram na expulsão dos indígenas e dos camponeses da região (Zoomers \& Kleinpenning, 1990: 109-125; Riquelme, 2003: 130).

Na década de 1960/70, com o desenvolvimento capitalista brasileiro liderado pelo Estado, o Brasil completou sua revolução verde, com a motomecanização, o melhoramento genético e a aplicação de insumos químicos industriais. Pode-se afirmar que a agricultura brasileira, nesse ensejo, evoluiu basicamente de vários complexos rurais, ou seja, vastas fazendas, grandes propriedades, que tinham nível de consumo interno e produção de subsistência no seu próprio domínio, para os chamados complexos agroindustriais (Graziano, 1994: 138-140). A modernização agrícola, conjugada com uma política de interesses das indústrias de equipamentos, de insumos e de transformação de matérias-primas, com forte predomínio das grandes multinacionais de países centrais, geraria a concentração fundiária e consequentemente 0 fenômeno do êxodo rural, expulsando milhares de pequenos agricultores para novas fronteiras agrícolas, inclusive para o Paraguai.

Além disso, a construção da Usina Binacional de Itaipu, entre 1973 e 1984, desalojou mais de 40 mil pessoas, em sua maioria lavradores do oeste do Paraná (Moraes \& Mattos, 2013: 40). A obra utilizou, ao lado de trabalhadores paraguaios, aproximadamente 100 mil trabalhadores brasileiros provenientes de várias regiões do país. Esses trabalhadores, após a conclusão da usina, precisaram buscar outras atividades para seu sustento. Muitos dos desalojados e dos ex-barrageiros de Itaipu foram seduzidos pelas políticas de incentivo e de atração adotadas pelo governo Stroessner (Itaipu Binacional, 2015). De 1954 a 1989, estima-se que foram concedidos mais de 12 milhões de hectares de terras a imigrantes brasileiros, atraídos pelos preços baixos praticados no Paraguai e repelidos pela situação econômica, social e política do Brasil. Os brasileiros se estabeleceram predominantemente em seis departamentos paraguaios: do Amambay, de Canindeyú, do Alto Paraná, de Itapúa e de Caaguazú (Fabrini, 2012: 1-9; Moraes \& Mattos, 2013: 40).

Em um primeiro momento, a maioria dos imigrantes brasileiros era de origem humilde e nunca chegou a ser proprietária de terras (apenas meeiros, parceiros, arrendatários ou empregados). A política de Stroessner, todavia, incentivou efetivamente a ida de grandes empresas brasileiras (madeireiras, agropecuárias, colonizadoras, bancárias, entre outras), que adquiriram terras a um preço bem abaixo do mercado (Zamberlam et al, 2007: 18). Em meados da década de 1970, surgiram as primeiras colônias brasileiras no Paraguai, onde passaram a predominar a língua portuguesa, os canais de televisão, as músicas e 
as tradições culturais do Brasil. Muitas delas contaram com o apoio significativo do IBR e tiveram como associados militares paraguaios vinculados à ditadura de Stroessner, além de empresas privadas.

O Paraguai, nesse período, iniciava sua revolução verde, que, assim como a brasileira, também fora financiada pelo Estado. Os espaços agrícolas, antes voltados para a subsistência ou consumo interno, transformaram-se, tal como aqui, em verdadeiros complexos agroindustriais, e em objeto de interesse da burguesia dominante voltada para a especulação fundiária. Isso favoreceu o surgimento de grandefúndios empresariais e monoculturistas, construindo-se estruturas produtivas marcadas pela relação de dependência dos empresários rurais em relação às companhias colonizadoras e ao mercado externo.

Nesse sentido, reproduziu-se no Paraguai a matriz empresarial-monopolista-agroexportadora, caracterizada pelo grandefúndio - em virtude de sua propensão a gerar a monopolização das propriedades e a espoliação dos pequenos proprietários graças ao capital mercantil e às frágeis relações trabalhistas -; pela especulação fundiária; pela gestão empresarial; pelo alto nível de capital de exploração; pelo uso de mão de obra assalariada; pelas linhas de exploração monoculturista, voltada exclusivamente para o mercado; pela presença de poucas mas poderosas corporações durante todo o ciclo produtivo; e pela baixa integração às cadeias de comercialização interna.

No fim da década de 1980, as propriedades disponíveis para arrendamento se extinguiram, assim como diminuíram as medidas governamentais de incentivo à produção agrícola. O Banco Nacional del Fomento do Paraguai, ajudado pelo Banco Interamericano de Desenvolvimento - BID, que vinha impulsionando a economia rural paraguaia, praticamente cortou os créditos agrícolas. As ações ocorreram em virtude da crise econômica da dívida externa e do esgotamento do modelo desenvolvimentista enfrentados pela maioria dos países latino-americanos naquele momento (RED RURAL, 1993: 17).

Essas medidas atingiram principalmente o modelo familiar-cooperativista-alimentício, concentrado nos pequenofúndios e nos mediofúndios - em razão das reproduções sociais e da manutenção da identidade familiar campesina -; na estrutura centrada na família; no baixo/ médio nível de capital de exploração, que o leva ao estabelecimento organizacional cooperativista ou associativista; na democratização da terra; na interação entre gestão e trabalho; na variação dos parceiros corporativos durante o ciclo produtivo; nas linhas de exploração diversificada, focando, todavia, na produção alimentícia com graus variáveis de mercantilidade interna e externa e servindo para o consumo próprio.

Nesse período, os médios e pequenofúndios, que não tiveram a oportunidade de se organizar adequadamente, necessitavam da política de preços mínimos, dos subsídios para 
compras de insumos, da redução ou eliminação de impostos para a aquisição de tratores e demais maquinários. As poucas propriedades rurais paraguaias pertencentes à estrutura campesina familiar não tiveram condições de concretizar o desenvolvimento capitalista rural. Faltou-lhes o apoio material e social-político para a solidificação de uma cultura associativa capaz de fazer prosperar uma exploração rural edificada na matriz familiar-cooperativista-alimentícia, permanecendo muitas delas na produção de subsistência.

Na "década perdida" de 1980, como ocorrera no Brasil, o Paraguai vivenciou um grande êxodo rural. Muitos trabalhadores rurais paraguaios e brasileiros descapitalizados, desamparados organizacionalmente e afundados em dívidas abandonaram ou perderam suas terras por determinação judicial ou pela concentração fundiária, restando-Ihes migrar para os grandes centros regionais. Vários camponeses expulsos de suas terras foram morar em áreas urbanas degradadas como favelas, cortiços ou debaixo de pontes. Houve um processo de lumpenização, de degradação do campesinato. Foi nesse contexto histórico que os imigrantes brasileiros que regressaram do país vizinho passaram a ser conhecidos como brasiguaios. $^{3}$

Os produtos de exportação, como a soja, foram priorizados, ignorando-se a demanda do mercado interno. Priorizou-se também a pecuária de corte, em detrimento a leiteira, e privilegiaram-se certas regiões política e economicamente mais poderosas (Sánchez, 1997: 238-241; Rivarola, 1981: 184). Houve, desse modo, o beneficio do modelo empresarial-monopolista-agroexportador, capitalizado não raramente por empresas e bancos financiadores do agronegócio monoculturista, centrado nas relações de expropriação do trabalho camponês, ou seja, na extração de mais valia do assalariado rural e não em sua dinâmica capitalista.

\section{MOVIMENTOS SOCIAIS NA LUTA PELA TERRA NO PARAGUAI}

E m 1989, o General Andrés Rodríguez Pedotti, ex-aliado e frequentador do ciclo pessoal de Stroessner - sua filha era casada com o filho mais novo do ditador -, liderou, juntamente com a ala tradicionalista do Partido Colorado e com o apoio de setores militares, políticos, religiosos e dos EUA, um golpe de Estado contra o governo. Após 35 anos de ditadura militar-personalista, o Paraguai foi às urnas para eleger o próprio Rodríguez, que, apesar de seu passado e de acusações em comum com Stroessner, se candidatou pelo Partido Colorado e obteve $74 \%$ dos votos. Seu governo, de cunho neoliberal, foi marcado pelas privatizações, pela assinatura do Tratado de Assunção em 1991, criando o Mercado Comum do Sul - Mercosul, e pela promulgação de uma nova constituição em 1992. 
As lideranças dos movimentos camponeses paraguaios - como a Asociación de Pequeños Productores Agrícolas (APPA), a Coordinación Juvenil Campesina (CJC), o Movimento Campesino Paraguaio (MCP), a Organización de Lucha por La Tierra (OLT) e a Cordinación Nacional de Productores Agrícolas (CONAPA), posteriormente Federación Nacional Campesina (FNC) - que se articulavam desde meados da década de 1980 em pequenas organizações para lutar pela reforma agrária e por melhores preços para as safras, vislumbraram na recente democracia uma possibilidade de lutar pelo direito de exploração da terra (Piñero, 2004: 125-130).

Em 1994, várias das entidades se uniram e criaram a Mesa Coordinadora Nacional de Organizaciones Campesinas (MCNOC). A organização nasceu com o objetivo de pressionar por uma reforma agrária no Paraguai, incentivadora do pequenofúndio, defensora da agricultura alimentícia, com gestão dos próprios campesinos organizados em cooperativas, para atender à demanda do mercado interno, proporcionando assim maior bem-estar social. Recentemente, entraram em sua pauta de reivindicações, além do combate à matriz produtiva empresarial-monopolista-agroexportadora do campo, a regulação das plantações transgênicas, a denúncia do uso indiscriminado de agroquímicos, a luta pela anistia das dívidas dos camponeses e a busca por mais créditos agrícolas.

Pela primeira vez, os movimentos sociais campesinos paraguaios estavam tendo possibilidades de pleitear a democratização da terra, gerando a incorporação de dezenas de famílias e lotes ao sistema produtivo rural, e de defender um novo modelo de exploração capitalista agrícola no país. Como ações de mobilização social, houve realizações de marchas e ocupações de grandefúndios, muitos pertencentes a brasileiros. Os imigrantes e o modelo de exploração da terra importado do Brasil eram vistos por esses movimentos como um dos responsáveis por acentuar as desigualdades existentes no país, o que resultou na deflagração de profundos conflitos.

De 1990 a 2004, os carperos, como são conhecidos os sem-terras paraguaios, foram responsáveis por 407 ocupações de grandefúndios. No mesmo período, houve ainda 885 conflitos pela posse da terra, 535 manifestações, 350 desocupações forçadas pelo Estado e a prisão de 7.018 sem-terras. De 1989 até 2006, ocorreu o assassinato de mais de 100 militantes campesinos (FIAN/Via Campesina, 2006: 6-17). Os carperos, não vendo suas demandas serem atendidas e sendo reprimidos violentamente por sucessivos governos paraguaios Juan Carlos Wasmosy (1993-1998), Raúl Cubas Grau (1998-1999), Luís González Macchi (1999-2003), Óscar Nicanor Duarte Frutos (2003-2008) -, apoiaram decisivamente, nas eleições de 2008, a Alianza Patriótica por el Cambio (APC). ${ }^{4} \mathrm{~A}$ aliança agregou relevantes partidos de centro-esquerda e pôs fim a seis décadas de governo do Partido Colorado - incluindo a 
ditadura de Stroessner - ao eleger, com 40,8\% dos votos, o ex-bispo da Igreja Católica e partidário da Teoria da Libertação Fernando Armindo Lugo de Méndez.

0 bispo vermelho, como era conhecido Lugo, chegou ao poder no Paraguai com expressivo apoio dos movimentos sociais, dos sindicatos e da Igreja, e com a promessa de difundir a justiça social no país. Durante sua formação, a APC conquistou a simpatia dos principais movimentos campesinos paraguaios, como a Coordinadora Nacional de Mujeres Rurales e Indígenas (CONAMURI), o Movimiento Agrario y Popular (MAP), as Coordinadoras Departamentales de Lucha por la Soberanía y la Vida (CDLSV), a Organización Nacional de Aborígenes e Indígenas (ONAI) e a própria MCNOC.

Lugo cativou o campesinato ao prometer em campanha que realizaria uma reforma agrária profunda e que reveria cerca de 7 milhões de hectares concedidos supostamente de maneira ilegal pelo governo Stroessner aos brasileiros. A reforma, contudo, nunca foi realmente concretizada. Além disso, o surgimento de escândalos da vida privada do presidente e as alianças políticas questionadas pela esquerda motivou a radicalização de determinados movimentos sociais e a organização de grupos como a Frente Nacional de Lucha por la Vida y la Soberanía (FNLSV), o Ejército del Pueblo Paraguayo (EPP) e a Associación Campesina Armada (ACA).

A FNLSV foi constituída em congresso realizado em 3 de julho de 2004 e reuniu a Central Nacional de Trabajadores (CNT), a Central Unitaria de Trabajadores Autentica (CUT-A), a Plenaria Popular Permanente (PPP), a Organización Nacional Campesina (ONAC), a CDLSV e a MCNOC. A frente se tornou um espaço de ação conjunta e permanente dos movimentos sociais paraguaios em defesa de um modelo alternativo de desenvolvimento urbano e rural, e opta por ações pacíficas, como bloqueios de estradas, marchas, manifestações, plebiscitos, acampamentos, entre outros mecanismos de ativismo social.

0 EPP, fundado em 2008, de orientação marxista-leninista, enveredou por outro lado pela a luta armada em 2010, principalmente nos departamentos de San Pedro e de Concepción. Em 2014, o EPP se dividiu, por desavenças entre as lideranças, surgindo assim a Associación Campesina Armada (ACA), com maior concentração em Arroyito, em Concepción. Os dois movimentos armados utilizam ações como sequestros, confrontos com a polícia e atentados para chamar a atenção e conquistar suas reivindicações.

As tensões entre o campesinato sem-terra paraguaio e os grandes fundiários brasileiros não têm todavia um caráter somente ideológico, socioeconômico e político: há uma questão étnica-cultural e anti-imperialista latente. A presença dos brasileiros no Paraguai, ${ }^{5}$ como em grande parte dos processos migratórios, produziu aspectos complexos nos locais de trabalho e de convívio social em determinadas regiões. Os ruralistas brasileiros no país, de 
modo geral, são de origem europeia, assim como era o General Stroessner, descendente de alemão, enquanto os carperos são predominantemente de origem guarani.

Pode-se dizer que, mormente nos departamentos onde brasileiros se estabeleceram, se desenvolveu aquilo que lanni (2004: 91-103) chama de um novo ciclo de racialização. Esse processo envolveu as diferentes formas de sociabilidade, gerando tensões étnicas, linguísticas e político-socioeconômicas. A população local, ao identificar no imigrante uma ameaça à sua simbologia, suas tradições e seu poder político-econômico, pode tender ao xenofobismo, ao etnicismo e ao racismo.

0 sentimento anti-imperialista em relação aos brasileiros ficou evidente em 20 de maio de 2007, por ocasião da visita do então presidente da República Federativa do Brasil, Luís Inácio Lula da Silva (2003-2010), ao Paraguai. Na ocasião, um dos principais jornais de Asunción, o $A B C$ Color, publicou um editorial com o seguinte título: "Brasil, un país imperialista y explotador".

Segundo setores da mídia, alguns movimentos sociais, entre eles os campesinos, e grupos acadêmicos e políticos paraguaios, o Brasil atua como subcentro, adotando padrões de reprodução da exploração do capital, tanto no campo como na cidade. 0 país, desse modo, exerce na região um subimperialismo que, de acordo com Marini (1992: 137-138), deve ser entendido não só por seu aspecto meramente institucional mas, sobretudo por suas determinações econômicas e de classe.

Ressalta-se, porém, que no substrato do conflito está a desigualdade de acesso à terra e o modelo de desenvolvimento da agricultura paraguaia.

Yo no estoy en contra de los inmigrantes brasileños, pero me preocupa lo que está pasando, la manera incontrolada en que están comprando tierras y forzando a los colonos paraguayos a vender sus chacras, provocando un éxodo masivo, además del grave daño al medio ambiente. (...) Las chacras se convierten en tierra pelada para plantar soja, se cierran las escuelas, se abandonan los ranchos y las comunidades se convierten en pueblos fantasmas (Padre Mario Sotelo apud Albuquerque, 2005: 160).

Há, portanto, dois caminhos para o desenvolvimento capitalista rural paraguaio. De um lado, a matriz empresarial-monopolista-agroexportadora defendida principalmente pelos grandes proprietários de terras, sobretudo os produtores de soja e de gado, estrangeiros e paraguaios; por empresas multinacionais, fornecedoras de insumos e maquinários agrícolas; pelo sistema financeiro e bancário; pela Asociación Rural del Paraguay (ARP) e por esferas da grande mídia. A outra via é o modelo de exploração familiar-cooperativista-alimentício que conta com o apoio dos carperos, de parte da intelectualidade acadêmica, de ordens religiosas, 
de setores da sociedade civil organizada, de pequenas cooperativas e associações rurais, de prestigiosas organizações internacionais, de espaços midiáticos alternativos, e com o suporte tácito de outros movimentos campesinos, como o Movimento dos Trabalhadores Rurais Sem Terra (MST) do Brasil.

O MST possui laços históricos profundos com a causa agrária do Paraguai, pois vários de seus militantes e de seus dirigentes são brasiguaios que regressaram do país vizinho nos meados de 1980 e encontraram apoio na organização fundada em 1984. Em 1985, em seu primeiro congresso, o movimento deixou claro além disso que a luta dos sem-terra não é um embate entre nações, mas um conflito entre classes (Rubbo, 2012: 23; Cortez, 1993: 46).

A MCNOC e o MST entendem que o Estado-nação está a serviço do capital oriundo da classe dominante, o qual quase nunca obedece a uma lógica produtiva igualitária e não raramente é especulativo e transfronteiriço. A exploração da classe privada de acesso aos fatores produtivos, desse modo, é a mesma em toda parte do mundo, e os trabalhadores teriam que se unir e lutar contra o adversário comum. Há, portanto, necessidade de construir laços de solidariedade e redes transnacionais de resistência entre o campesinato mundial na luta pela democratização do acesso à terra por meio da reforma agrária, pela agricultura familiar, pela criação de cooperativas, contra o uso indiscriminado de sementes transgênicas, de insumos agrícolas e de agrotóxico (MST, 2015; Via Campesina, 2015).

As relações, portanto, devem ocorrer interclasses, ou intermovimentos, e não inter-Estados. Essa posição fica clara na decisão dos dois movimentos sociais de não participar da Reunião Especializada sobre Agricultura Familiar (REAF) do Mercosul. As organizações afirmam que o Mercosul e a REAF não são os fóruns adequados para defender suas demandas (Bülow \& Carvalho, 2012: 235).

A MCNOC e o MST defendem que as relações entre o campesinato mundial ocorram de forma direta ou via redes de ação coletivas e laços de solidariedade. Estabelecem assim fóruns de partilhas, de debates e de ajuda mútua, como a Coordenadora Latino-Americana de Organizações do Campo (CLOC), a Food First Information and Action Network (FIAN), a Via Campesina e o Fórum Social Mundial, entre outros.

Evidencia-se que o movimento transnacional campesino avalia que o atual modelo econômico capitalista de exploração rural e acumulação de capitais, gerador de desigualdades, transbordou as fronteiras do Estado-nação. A cooperação entre classes, assim, por meio do ativismo internacional ou sem intermediários, com a formação de brigadas internacionais que visitam países e ajudam a construir movimentos camponeses na região, é fundamental para reconfigurar a infraestrutura local, regional e mundial. 


\section{NOVOS CENÁRIOS E VELHOS ATORES}

E

m junho de 2012, o enfrentamento pela terra no Paraguai resultou na morte de 17 pessoas na cidade de Curuguaty, de dez carperos e sete policiais no departamento de Canindeyú. Após esses acontecimentos, e descontentes com as manifestações de grupos socialistas na sede das Forças Armadas, o Congresso Nacional do Paraguai, com respaldo no texto constitucional, cassou em julgamento sumário o mandato de Lugo como presidente da República. 0 vice-presidente Luis Federico Franco Gómez assumiu então a presidência pelo Partido Liberal Radical Auténtico (PLRA). Nos primeiros dias de seu mandato, Franco Gómez adotou medidas beneficiando a matriz empresarial-monopolista-agroexportadora e o grandefúndio, entre as quais se destacavam a lei que permitia a negociação, a preço de mercado, de terras destinadas à reforma agrária; a suspensão, por decreto, de auditoria nas terras do megaempresário Tranquilo Favero, ${ }^{6}$ e a autorização do plantio de sementes transgênicas de algodão e de soja.

A utilização de sementes transgênicas, sobretudo a variedade Roundup Ready (RR), patenteada pela influente multinacional Monsanto, atualmente responde por $70 \%$ da produção de soja no Paraguai (USDA, 2012). Segundo o Ministerio de Agricultura y Ganadería (MAG), o plantio de soja abrange 3.080 .000 hectares, na sua maioria em terras com bons solos como Alto Paraná, Canindeyú, fronteira com o Brasil, Itapúa, divisa com a Argentina (Paraguay, Síntesis Estadística Producción Agropecuaria, 2012-2013).

0 uso da soja transgênica contribuiu para o aumento da dependência dos produtores da única empresa e para a falta de diversidade na produção agrícola, gerando pressão inflacionária nos alimentos e queda na qualidade alimentar dos paraguaios, principalmente para os cidadãos de baixa e média renda. A expansão da monocultura, ademais, aumentou o valor do hectare, no prazo de uma década, em mais de $1.000 \%$, inviabilizando assim a formação de cooperativas familiares voltadas para a demanda interna (Viladesau, 2005: 40).

Com uma produção de 9.086.000 toneladas de grãos de soja por ano, o Paraguai se transformou no $6^{\circ}$ maior produtor e no $4^{\circ}$ maior exportador mundial da soja em grão (USDA, 2012; Banco Mundial, 2013). 0 país exporta cerca de 60\% dessa produção a granel, já que a capacidade e a infraestrutura produtiva para agregar maior valor à commodity - como sua transformação em farelo, óleo, biodiesel, produtos nobres da oleaginosa ou outros derivados - precisam de mais investimentos (Paraguay, CAPECO, 2014).

A soja representa, aproximadamente, 9\% do PIB do Paraguai, 81\% do PIB agrícola, 55\% dos ingressos de divisas por exportações, US\$ 3 milhões em investimentos e 
250 mil postos de trabalho (Idem). A contribuição tributária desse setor para o governo paraguaio é contudo insignificante. Isso ocorre pelo fato de que, no Paraguai, a legislação tributária não prevê a cobrança de impostos para a exportação de grãos in natura, e o tributo sobre a propriedade rural, cobrada pelos municípios, não representa o valor de mercado da terra.

Para tentar mudar tal cenário, em outubro de 2013 o Congresso Nacional aprovou a Ley $n^{\circ} 5082$ de reforma tributária. A lei taxaria as exportações a granel de soja, trigo, milho e girassol em 10\%. Em 16 de outubro de 2013, entretanto, o recém-empossado presidente Horacio Manuel Cartes Jara, do Partido Colorado, com o Decreto $\mathrm{n}^{\circ} 487$, vetou integralmente a lei (Informativo Campesino, 2014; Paraguay, Decreto $n^{\circ} 487 / 2013$ ). Segundo os defensores do projeto, o governo paraguaio arrecadaria em torno de US\$ 300 milhões anuais (Desantis, 2013).

Embora a monocultura da soja no Paraguai seja fundamental para compreender a produção empresarial agrícola do país, a criação de gado de corte é a que mais monopoliza espaço. Realizada quase toda de forma extensiva, ela ocupa atualmente 57,5\% dos 31 milhões de hectares disponíveis para a exploração rural (Paraguay, SENACSA, 2014), e é responsável pela abertura da nova fronteira agrícola no país, o avanço para a região ocidental, o Chaco. A região, semiárida e lar de povos indígenas milenares, antes preservada e com uma baixa densidade populacional, está em plena transformação. Investidores, mormente, estrangeiros - brasileiros e europeus - estão adquirindo grandes porções de terras, realizando um desmatamento desenfreado e expulsando comunidades locais tradicionais (Carneri, 2015).

0 avanço da pecuária nessa região, que assim como a Amazônica representa uma das últimas fronteiras agrícolas da América do Sul, fez com que a produção de carne exportada pelo Paraguai saltasse de 81.770.331 quilos em 2004 para 268.940.029 quilos em 2014, sendo que somente de 2013 para 2014 houve um aumento de mais de 77 mil quilos. Se, em 2004, os rendimentos recebidos das exportações de carnes e do subproduto de origem animal representavam somente US\$204.609.881, atualmente esse valor está em US\$ 1.637.248.571 e corresponde a 5\% do PIB do Paraguai (Paraguay, SENACSA, 2014; $B C P, 2014)$.

A especulação e a corrupção fundiária com terras estatais nos departamentos do Chaco fizeram com que os lotes na região se supervalorizassem em um curto período de tempo. Segundo Justo Cárdenas, presidente do Instituto Nacional de Desarrollo Rural e de la Tierra (Indert), que substituiu o antigo IBR em 2004, há dez anos o hectare era vendido a US\$ 6,25, enquanto atualmente seu valor alcança US\$ 400 ou mais (Daniels, 2011). 
Enquanto a matriz empresarial-monopolista-agroexportadora, produtora principalmente de carne e de soja, e viabilizada, em virtude de sua dinâmica, especialmente em grandefúndios, avança no Paraguai, o modelo familiar-cooperativista-alimentício voltado para o consumo interno, para melhoraria do bem-estar social e para a busca de soberania alimentar é negligenciado. Produtos como leguminosas, verduras, frutas e determinados tipos de carnes possuem preços elevados em razão do alto custo de produção e escoamento, além de sofrer pressão inflacionária por causa da baixa oferta.

No ano de 2011, trabalhadores rurais, aduaneiros e taxistas fecharam a Ponte Internacional da Amizade como forma de se manifestar contra os altos preços dos alimentos paraguaios. Essa escassez de produto e o preço elevado de alguns itens alimentares fazem com que haja um forte contrabando, por parte dos paraguaios, de produtos de alimentação oriundos do Brasil, como banana, maçã, tomate, cebola, alho, frango e ovos.

No Paraguai, o conceito de agricultura familiar foi referenciado pelo Estado somente na Ley $n^{\circ} 1.863$ de 2002, que estabeleceu o Estatuto Agrario. 0 artigo 2, que se refere ao tema, e posterirormente a Ley 2002/02, que o modificou, citam a expressão agricultura familiar de forma vaga e não regulamentada, complicando desse modo a aplicação do conceito na estrutura agrária do país.

0 campesinato local, portanto, não conta com um amparo legislativo e político que incentive o fortalecimento das atividades desenvolvidas pelos médios e pequenofúndios familiares. Há apenas políticas pontuais, como o Projeto para o Fortalecimento do Programa de Alimentação Escolar Sustentável (PAES), uma cooperação Paraguai-FAO-Brasil que estimula a comercialização dos produtos da agricultura familiar a serem utilizados por instituições públicas como hospitais e escolas.

Os médios e pequenofúndios paraguaios carecem de um projeto político respaldado por uma legislatura específica que possibilite a combinação entre a gestão cooperativista e o trabalho rural familiar, gerando a diversificação produtiva e o desenvolvimento do capitalismo rural responsável. Esses dispositivos regulatórios burocráticos, acompanhados de financiamentos estatais, proporcionaria ao agricultor familiar e ao cooperado aumento da renda, do valor agregado ao produto e à propriedade, mediante a modernização do sistema produtivo, a valorização do produtor rural, a profissionalização dos trabalhadores familiares e sua plena integração nas cadeias produtivas capitalistas da agricultura moderna. 


\section{CONSIDERAÇÕES FINAIS}

$\mathrm{O}$

Paraguai, desde seu período como colônia espanhola no início do século XVI até 1989, jamais havia tido a experiência de um governo de fato democrático. Independente da coroa espanhola em 1811, o país construiu sua história política recente através de uma sequência ininterrupta de autoritarismos estruturados no poder por meio de tiranias paternalistas ou de oligarquias. Os governantes paraguaios, excluindo a incompleta e conturbada experiência de incentivo à produção agrícola campesina durante a ditadura de José Gaspar Rodríguez Francia (1814-1840), representaram os interesses de uma elite rural atrasada, que resistiu ao longo dos anos independentemente das mudanças de forças intra-classe ou de coalizões extra-classe.

A adoção da matriz empresarial-monopolista-agroexportadora teve expressiva contribuição econômica de empresas e de colonos brasileiros. Politicamente, no entanto, são os paraguaios ruralistas, ou os cooptados por estes, que fazem as regras da estrutura fundiária. Essa estrutura, alicerçada quase que integralmente no padrão semicolonial da monocultura de commodities, especialmente a soja e a carne, para a exportação, com um ciclo de produção e de negociação dominado por poucas empresas multinacionais, menospreza a soberania, a segurança alimentar, a dinâmica do mercado interno, o bem-estar social, inviabilizando a autogestão e a expansão do mercado de consumo no país.

A desigualdade de acesso à terra no Paraguai é evidente, e a presença dos médios e pequenofúndios é ínfima, mesmo adotando-se medidas de análises generosas, como as estabelecidas pelo presente estudo. Observa-se que o grandefúndio, concentrado nas mãos de poucas pessoas, representa $84,8 \%$ de todas as propriedades rurais do país (Paraguay, Síntesis Estadística Producción Agropecuaria, 2012-2013). Esse cenário faz com que os cidadãos paraguaios, marginalizados do consumo, cheguem à agonia de contrabandear alimentos em razão do elevado preço no mercado interno.

O Paraguai necessita quebrar essa estrutura social, econômica e política vigente há décadas, sendo a atuação dos movimentos sociais como a FNLSV determinante para tanto. Setores dominantes da burguesia rural paraguaia conseguem, por exemplo, derrubar leis que taxariam suas produções em valores justos e aumentariam a arrecadação estatal.

A MCNOC, que, juntamente com o MST, pode ser considerada um dos maiores movimentos campesinos da América Latina, apologista do modelo familiar-cooperativista- alimentício de exploração rural, além de se estruturar internamente, necessita expandir seu ativismo local para os níveis regional e internacional. A cooperação com outras organizações campesi- 
nas e a articulação em redes transnacionais de resistência é imprescindível, porém não se deve desconsiderar os fóruns institucionalizados, como a REAF do Mercosul, valorosos palanques onde a causa ressoa.

Infere-se que o governo paraguaio somente solucionará a violência do campo, a expulsão do campesinato, a favelização, a expansão horizontal das periferias urbanas, o mercado informal de alimentos e de outros produtos e o recente conflito étnico-cultural com a redistribuição de lotes pela via judiciária. A reforma agrária - dando prioridade à distribuição de lotes para a exploração familiar, com gestão cooperativista, e para a produção de alimentos voltada para o mercado interno, de início com o apoio creditício, técnico e comercial do Estado - desvencilharia o Paraguai do tormento latifundiário, distribuiria renda, incorporaria milhares na dinâmica capitalista de produção e de consumo, beneficiando a economia do país ao diminuir a pressão inflacionária dos alimentos, e torná-lo-ia menos depende das flutuações do mercado internacional.

\section{NotAS}

1 Os valores de hectares apresentados pela pesquisa foram estruturados com base na vasta bibliografia e em diversos estudos de limites das áreas agrícolas. Além disso, observaram as particularidades do Paraguai, dimensão territorial, organização do espaço e aspectos culturais, políticos e socioeconômicos. Para exemplos de limites de propriedades em outras nações ver Carter (2010: 48).

2 Itaipu transformou o Paraguai no maior produtor de energia per capita do mundo, com seu excedente energético exportado obrigatoriamente para o Brasil, de acordo com o tratado, até 0 ano de 2023. No ano de 2013, a venda de energia elétrica representou 6,7 \% do PIB paraguaio (Paraguay, DGEEC, 2013).

3 Em 1985, na cidade de Mundo Novo (MS), durante manifestação de brasileiros que haviam regressado do Paraguai, um imigrante indagou ao deputado Sérgio Cruz: "Então nós não temos os direitos dos paraguaios porque não somos paraguaios; não temos os direitos dos brasileiros porque abandonamos o país. Mas, afinal de contas, me diga: o que nós somos?" O deputado respondeu: "Vocês são uns brasiguaios, uma mistura de brasileiros com paraguaios, homens sem pátria". Ver Wagner (1990: 11-17).

4 Os partidos que compunham a APC eram: Partido Revolucionário Febrerista; Partido Democrata Cristão do Paraguai; Partido País Solidário; Partido da Frente Ampla; Partido Encontro Nacional; Bloco Social e Popular; Partido Social Democrata; Avancemos; Poder Cidadão em Ação; Movimento de Participação Cidadã.

5 Não existem dados precisos sobre o número de imigrantes brasileiros no Paraguai, pois muito deles possuem dupla cidadania. Portanto, ora se declaram paraguaios, ora brasileiros, de acordo com a conveniência. Levantamento do governo paraguaio em 2002 estimava que houvesse 81.592 brasileiros no país (Paraguay, DGEEC, 2013). 0 Ministério das Relações Exteriores brasileiro chegou à estimativa de 459.760 em 2012, e 0 Instituto Brasileiro de Geografia e Estatística, de 4.926 em 2010, número muito inferior aos apresentados pelo MRE e pelas pesquisas oficiais do Paraguai. 0 estudo acredita que os mais próximos da realidade sejam os 
dados oriundos do MRE em virtude de sua grande capilaridade no país vizinho e na prestação de assistência aos migrados daquele país.

6 Tranquilo Favero é brasileiro naturalizado paraguaio. É o maior produtor individual de soja do país. Favero comanda um conglomerado de sete empresas que ocupam terras em 13 dos 17 departamentos, muitas delas, segundo o movimento campesino, terras públicas.

\section{REFERÊNCIAS BIBLIOGRÁFICAS}

ALBUQUERQUE, José L. Campesinos paraguayos y "brasiguayos" en la frontera este del Paraguay. In FORGEL, Ramón \& RIQUELME, Marcial (org.). Enclave sojero, merma de soberanía y pobreza. Asunción: Centro de Estudios Rurales Interdisciplinarios (CERI), 2005.

BANCO MUNDIAL. Países: Paraguay. Washington, 2013. Disponível em: <http://data.worldbank.org/indicator/SL.AGR.EMPL.ZS>. Acesso em 16 de maio de 2015.

BRASIL. Ministério das Relações Exteriores. Estimativas populacionais das comunidades brasileiras no mundo - 2012. Retirado do apêndice da publicação Diplomacia Consular. Disponível em: <http://www.brasileirosnomundo.itamaraty.gov.br/a-comunidade/estimativas-populacionais-das-comunidades>. Acesso em 5 de setembro de 2014.

Instituto Brasileiro de Geografia e Estatística - IBGE. Censo 2010. Disponível em: <http://censo2010. ibge.gov.br/pt/resultados>. Acesso em 3 de junho de 2015.

Brasil, un país imperialista y explotador. $A B C$ Color. Asunción, 20 de mayo de 2007. Disponível em: <http:// www.abc.com.py/edicion-impresa/editorial/brasil-un-paisimperialista y-explotador-982863.html>. Acesso em 5 de junho de 2015.

BÜLLOW, Marisa Von \& CARVALHO, Priscila Delgado. Entre o nacional e o transnacional - 0 caso das organizações da agricultura familiar no Mercosul. In: GOHN, Maria da Glória \& BRINGEL, Breno M. (orgs.). Movimentos sociais na era global. Petrópolis: Vozes, 2012.

CARNERI, Santi. Estância de gado no Paraguai é investigada por genocídio. Agência EFE - Revista Exame. Asunción. Disponível em: <http://exame.abril.com.br/mundo/noticias/ estancia-de-gado-no-paraguai-e-investigada-por-genocidio>. Acesso em 17 de junho de 2015.

CARTER, Miguel. Combatendo a desigualdade social: o MST e a reforma agrária no Brasil. São Paulo: Unesp, 2010.

CORTEZ, C. Brasiguaios: os refugiados desconhecidos. Campo Grande: Brasil-Agora, 1993.

DANIELS, Afonso. Febre da terra transforma Chaco paraguaio em 'inferno'. Asunción: Opera Mundi. Disponível em: <http://brasildefato.com.br/node/6870>. Acesso em 18 de junho de. 2015.

DESANTIS, Daniela. Paraguai aprova imposto sobre exportação de grãos. Reuteurs Brasil. Disponível em: <http://br.reuters.com/article/worldNews/idBRSPE999 01H20131010 >. Acesso em 21 de junho de 2015. 
FABRINI, João Edmilson. Campesinato e agronegócio na fronteira entre o Brasil e Paraguai. Boletim DATALU$T A$, v. 23, p. 1-9, 2012.

FAO. Food and Agriculture Organization. Concentración y extranjerización de la tierra en América Latina. Roma: Publications. Disponível em: <http://www.rlc.fao.org/fileadmin/content/events/semtierras/ acaparamiento.pdf>. Acesso em 14 de maio de 2015.

FIAN \& VIA CAMPESINA. La reforma agraria en Paraguay. Asunción: FIAN Informe R8. Disponível em <http:// www2.ohchr.org/english/bodies/cescr/docs/infongos/ fianparaguay.pdf>. Acesso em 13 de maio de 2015.

FRUTOS, Juan Manuel. Con el hombre y la tierra, hacia el bienestar rural. Asunción: Cuadernos Republicanos, 1982.

GALEANO, L. Modernización agraria, diferenciación campesina y escenarios políticos. In: Procesos agrarios y democracia en Paraguay América Latina. Asunción: Centro Paraguayo de Estudios Sociológicos, p. 19-42, 1990.

GRAZIANO da Silva, José. 0 desenvolvimento do capitalismo no campo brasileiro e a reforma agrária. In: STÉDILE, João Pedro (coord). A questão agrária hoje. Porto Alegre: Ed. Universidade, 1994.

GUEREÑA, Arantxa \& RIQUELME Quintín. Espejismo de la soja. Asunción: Informes de Investigación de Oxfam, agosto de 2013. Disponível em <https://www.oxfam.org/sites/www.oxfam.org/files/rr-soy-mirage-corporate-social responsibility-paraguay-290813-es.pdf>. Acesso em 1 de junho de 2015.

IANNI, Octavio. Capitalismo, violência e terrorismo. Rio de Janeiro: Civ. Brasileira, 2004.

IICA. Instituto Interamericano de Cooperación para la Agricultura. Indicadores Agricultura: Región Sur - Paraguay. San José: CAESPA, 2012. Disponível em <http://www.iica.int/Esp/Programas/AnalisisEstrategico/Paginas/Indicadores Agricultura.aspx>. Acesso em 10 de junho de 2015.

INFORMATIVO CAMPESINO. Paraguay: Centro de Documentacion y Estudos - CDE, n 257; abril, maio e junho de 2014. Disponível em: <http://www.cde.org.py/web/attachments/article/160/Infocampesino_n257. pdf>. Acesso em 6 de maio de 2015.

ITAIPU BINACIONAL. Nossa história. Foz do Iguaçu, 2015. Disponível em: <https://www.itaipu.gov.br/nossa-historia>. Acesso em 12 de junho de 2015.

MARINI, Ruy Mauro. América Latina: dependência e integração. São Paulo, Brasil Urgente, 1992.

MORAES, Isaías A. \& MATTOS, Beatriz R. B. Brasiguaios e carperos: direitos e controvérsias na busca pela posse da terra no Paraguai. Revista de Geopolítica, Ponta Grossa, v. 4, nº 1, p. 36- 51, jan./jun. 2013.

MST. Solidariedade internacional. Brasil. Disponível em: <http://www.mst.org.br/solidariedade-internacional/>. Acesso em 5 de junho de 2015.

NICKSON, Robert Andrew. El regimen de Stroessner (1954-1989). In: TELESCA, Ignacio. Historia del Paraguay. Asunción: Taurus - Santillana, 2010.

PARAGUAY. Banco Central del Paraguay - BCP. Estadísticas Económicas. Disponível em: <https://www.bcp. gov.py/estadisticas-economicas-i359>. Acesso em 14 de junho de 2015. 
Cámara Paraguaya de Comercializadores y Exportadores de Cereales y Oleaginosas - CAPECO. Estadisticas. Disponível em: <http://www.tera.com.py/capeco/>>. Acesso em 10 de maio de 2014.

Censo Agropecuario Nacional - CAN 2008. Disponível em: <http://www.mag.gov.py/Censol Book\%201.pdf>. Acesso em 20 de maio de 2015.

Decreto $n^{\circ} 487$ de 16 de outubro de 2013. Objeta el projecto de Ley n 5082/2013. Disponível em: <http://www.presidencia.gov.py/archivos/ documentos/presidencia0b2ea5fb5b55cec2c2b9ee70fffbc2b3e51169ee8af929d6469a2320c8d94b06.pdf>. Acesso em 15 de abril de 2015.

. Dirección General de Estadística, Encuestas y Censos - DGEEC. Compendio Estadístico 2013. Publicaciones DGEEC, 2013. Disponível em: <http://www.dgeec.gov.py/Publicaciones/Biblioteca/compendio\%20 2013/Compendio\%20Estadistico\%202013.pdf>>. Acesso em 15 de maio de 2015.

Ley No 1.863 de 2002 que establece el Estatuto Agrario. Disponível em: <http://www.mag.gov.py/ Ley\%201863-02.pdf>. Acesso em 13 de maio de. 2015.

Ley No 2002/02 que modifica varios artículos de la Ley No 1863/02 Estatuto Agrario. Disponível em: <http://www.mag.gov.py/Ley\%201863-02.pdf> Acesso em 13 de maio de 2015.

Servicio Nacional de Calidad y Salud Anima - SENACSA. Estadística Pecuaria 2014. Disponível em: $<$ <ttp://www.senacsa.gov.py/index.php/servicios/estadisticas>. Acesso em 13 de maio de 2015.

. Síntesis estadística producción agropecuaria, 2012-2013. Disponível em: <http://www.mag.gov.py/ index-censo2014.php?pag=sintesis-estadistica.html>. Aceso em 13 de maio de 2015.

PIÑERO, Diego. Em busca de la identidad - La acción colectiva en los conflitos agrários de América Latina. Buenos Aires: Clacso, 2004.

PNUD. Ranking IDH Global 2013. Brasília, 2013. Disponível em: <http://www.pnud.org.br/atlas/ranking/ Ranking-IDH-Global-2013.aspx>. Acesso em 20 de maio de 2015.

RED RURAL. Participación y organización campesina. Serie Red Rural. Asunción: Ediciones RR n 4, 1993.

RIQUELME, Quintín. Los campesinos sin tierras en Paraguay: conflictos agrarios y movimiento campesino. Buenos Aires: CLACSO, 2003.

RIVAROLA, Domingo. Modernización agraria y diferenciación campesina. Revista Paraguaya de Sociología. Asunción, año 18, n 52, 1981.

RUBBO, Deni Ireneu Alfaro. Do campo para mundo: em busca de um internacionalismo continental para o MST - Entrevista com Gilmar Mauro. Revista Lutas Sociais, São Paulo, n. 29, p. 21-30, jul.-dez. 2012. Disponível em: http://revistas.pucsp.br/index.php/ls/article/view/18475. Acesso em 10 de junho de 2015.

SÁNCHEZ, B. Políticas agrarias y desarrollo: Paraguay 1954-1994. Asunción: Amambay, 1997.

USDA. United States Department of Agriculture. Publications - Census of agriculture. Disponível em: <http:// www.agcensus.usda.gov/Publications/>. Acesso em 20 de junho de 2015.

VIA CAMPESINA INTERNACIONAL. Paraguay: comunicado de la Mesa Coordinadora Nacional de Organizaciones Campesinas. Disponível em: <http://viacampesina.org/es/index.php/acciones-y-eventos-mainme- 
nu-26/17-de-abril-dde-la-lucha-campesina-mainmenu-33/694-paraguay-comunicado-de-la-mesa-coordinadora-nacional-de-organizaciones-campesinas>. Acesso em 15 de junho de 2015.

VILADESAU, Tomás Palau. El movimiento campesino en el Paraguay: conflictos, planteamientos y desafíos. Observatório Social de América Latina (OSAL), ano 6, n. 16, 2005.

WAGNER, Carlos. Brasiguaios: homens sem pátria. Petrópolis: Vozes, 1990.

ZAMBERLAM, Jurandir et al. Emigrantes brasileiros no Paraguai - presença scalabriniana. Coleção Pastoral \& Migrações. Porto Alegre: Solidus, 2007.

ZOOMERS, E. B. \& KLEINPENNING J. M. P. Colonización interna y desarrollo rural: el caso de Paraguay. Revista Geográfica I.PG.H. México, n 112, p. 109-125, 1990. 